\title{
Study on the Innovative Strength of Chinese Corporations and Innovation Education
}

\author{
Zhen Kong ${ }^{1, ~ a}$, Kun Bai ${ }^{2, ~ b, ~ *, ~ L i n g h a n ~ K o n g ~}{ }^{3}$ \\ ${ }^{1}$ Beijing Information Technology College, No. 5, Fangyuanxilu, Chaoyang District, \\ Beijing, China \\ ${ }^{2}$ University of International Relations, No. 12, Poshangcun, Haidian District, \\ Beijing, China \\ ${ }^{3}$ Beijing Bayi School, No. 29, Suzhoujie, Haidian District, Beijing, China \\ ${ }^{a}$ Kongz@bitc.edu.cn, ${ }^{b}$ Baikun@uir.edu.cn \\ *Corresponding author
}

\begin{abstract}
Innovation's centrality and importance in international operations has been a subject of enduring debate in the age of globalization. Cross-border knowledge spillovers and the race between nations for increased innovativeness only underscore the importance of innovation. One aspect of this discussion concerns the effect of national education on the ability to be innovative. The findings support the claim that most education aspects still demonstrate strong and lasting impact on the tendency to innovate at the national level. China's strong emphasis on innovation is shining through, and the government is making a strong commitment in many vital fields to ensure this continues to be the case.
\end{abstract}

KEYWORDS: Innovation; Chinese corporation; GDP; Education.

\section{Introduction}

Fueled by the government's strong emphasis on an innovation-driven economy, China for the first time joined the world's top 25 most-innovative economies. In manufacturing, China's extensive ecosystem has provided an unmatched environment for efficiency-driven innovation. The country has the world's largest and most highly concentrated supplier base, a massive manufacturing workforce, and a modern logistics infrastructure. These advantages give Chinese manufacturers a lead in some important knowledge-based manufacturing categories, such as electrical equipment, construction equipment, and solar panels. Today, Chinese companies improve their efficiency with a variety of cutting-edge approaches, including agile manufacturing, modular design, and flexible automation. The apparel manufacturer Everstar, for example, uses automated equipment and online design and e-commerce systems that help consumers to customize designs for clothing and 
receive finished goods within 72 hours. China is also pioneering the use of open manufacturing platforms. The challenges are mounting, however. As wages rise, the country becomes less competitive for the most labor-intensive work. At the same time, a worldwide transition is under way toward a new kind of manufacturing, sometimes called Industry 4.0: a much more intense digital linkage of manufacturing components, processes, and logistics. As a result, Chinese companies will face pressure to improve their performance in utilizing assets, matching supply with demand, and controlling quality. Success will depend on how well China can exploit the scale of today's manufacturing ecosystems and clusters to extend their benefits beyond individual factories through digitally linked networks. Some efforts are under way to mobilize rapid, flexible manufacturing. In Guangdong province, for example, manufacturers have set up joint platforms to share the benefits of R\&D and operations among companies in the same clusters. Elsewhere, companies are looking at ways to mass-customize products by combining flexible manufacturing with the aggregation of a huge Internet consumer base. New manufacturing gains may also emerge from the aggressive use of robots, which could make China's huge pool of semiskilled factory workers more effective.

\section{The new era of innovation}

Inheriting from the past and ushering in the future, the Chinese society has entered a new phase, standing on the center stage of the world. The vibrant new era has made hundreds of millions of Chinese people enjoy the convenience and beauty of living. Reshaping innovation mechanism, inspiring creativity while cultivating emerging business types and new markets, these endeavors not only elevate people's happiness, but also infuse new energy for transforming and upgrading various fields of economy. Innovation means to lead an era. "Innovation" will be both a major theme and preoccupation, given even more importance this year after pronouncements from Party General Secretary Xi Jinping in his work report at last fall's 19th National Congress of the Communist Party of China, regarding the shape of the new era and the new principal contradiction, both inextricably linked to accelerated advance of innovation in numerous fields. Numerous Chinese technology corporations owe their success to innovation and hard work, and are marching onto the global stage. Whether it be through foreign resource strategies or recruiting international talent at overseas research centers, Chinese corporations are gradually expanding outside the country in this emerging new age.

\section{Maintaining innovation momentum}

To date, when we have evaluated how well Chinese companies commercialize new ideas and use them to raise market share and profits and to compete around the world, the picture has been decidedly mixed. China has become a strong innovator in areas such as consumer electronics and construction equipment. Yet in others-creating new drugs or designing automobile engines, for example-the country still isn't globally competitive. That's true even though every year it spends 
more than $\$ 200$ billion on research (second only to the United States), turns out close to 30,000 $\mathrm{PhDs}$ in science and engineering, and leads the world in patent applications. Innovative startups that have their roots in technology commercialization are often known for successful products in the early stage of their operations. However, such successes will in turn create a market and inevitably attract more latecomers to enter the market. While early entrants, to a certain degree, will have an advantage, it does not mean that they can afford to rest and do nothing. Companies have to keep striving to innovate in order to defend their positions in the business against competitors. A company's innovation momentum can be boosted by adopting the following strategies: The original department led innovation model is replaced by the current product manager led innovation model. Mistakes are allowed to ensure employees keep an open mind. A number of incentives, including stock options, bonuses and chances of promotion, are provided and adjusted regularly according to contributions employees make to their job. Innovation always begins with people. A lack of excellent employees often leads to a lack of good ideas or effective execution of good ideas. The bosses will allocate a lot of resources to support their new products. Changes may have already taken place.

\section{Providing enough training}

Chinese Premier Li Keqiang said China needs to step up efforts to encourage innovation to develop new locomotives for the Chinese economy. New development modes and management patterns are a prerequisite for education transformation and upgrades. Breakthroughs must be made in mobilizing the innovativeness of talent through changing the present mode of education management. When we look ahead, though, we see broad swaths of opportunity. Our analysis suggests that by 2025, such new innovation opportunities could contribute \$1.0 trillion to \$2.2 trillion a year to the Chinese economy-or equivalent to up to 24 percent of total GDP growth. To achieve this goal, China must continue to transform the manufacturing sector, particularly through digitization, and the service sector, through rising connectivity and Internet enablement. Additional productivity gains would come from progress in science- and engineering-based innovation and improvements in the operations of companies as they adopt modern business methods. To develop a clearer view of this potential, we identified four innovation archetypes: customer focused, efficiency driven, engineering based, and science based. We then compared the actual global revenues of individual industries with what we would expect them to generate given China's share of global GDP (12 percent in 2013). As the exhibit shows, Chinese companies that rely on customer-focused and efficiency-driven innovation-in industries such as household appliances, Internet software and services, solar panels, and construction machinery-perform relatively well. China benefits from the sheer size of its consumer market, which helps companies to commercialize new ideas quickly and on a large scale; even a relatively small market like online gaming is bigger than the auto industry in Turkey or Thailand. Chinese companies have learned how to read the requirements of their rapidly urbanizing country and to scale up new products and services quickly to meet them. Manufacturers of appliances and other household goods dominated the first wave of 
customer-focused innovators in China. Their innovations were "good enough" products such as refrigerators and TV sets. But these offerings no longer suffice to gain a growing share of consumers. Companies like smartphone manufacturer Xiaomi are responding with cheaper and better products designed to offer hardware features as good as those from global brands but priced for the Chinese market. Like other customer-focused innovators in China, Xiaomi also uses the massive consumer market as a collaborator, rapidly refining its offerings through online feedback. Internet service providers are another hotbed of customer-focused innovation. Alibaba, Baidu, and Tencent have become global leaders in online services, largely thanks to their success in the enormous Chinese market. (For more, see "Five keys to connecting with China's wired consumers.”)Customer-focused innovation could reshape large swaths of China's service sector, where productivity lags behind that of its counterparts in developed economies. The government already is pushing to modernize traditional businesses through its Internet Plus initiative, announced in early 2015. Innovations are needed to expand access to services (for example, remotely monitoring the health of rural patients), to improve the quality of offerings (greater choice and customization in financial and educational products), and to optimize operations (crowd-sourced logistics). Chinese companies will also have opportunities to use their skills in customer-focused innovation to take a lead in selling to other emerging markets. Chinese educators have also taken notice of the lack of innovation. China will have to learn how to balance its old successes with a new way of thinking if it wants to compete.

\section{Engineering-based Innovation in Learning Industries}

Entrepreneurs are poised to play a bigger role. In Shenzhen, a rich ecosystem of component suppliers, design services, business incubators, and outsourced assembly capacity has helped start-ups prototype products and scale up global manufacturing businesses quickly. China has had mixed success with engineering-based innovation. The best performers are found in Chinese markets where motivated domestic industries are nurtured by national and local governments that create local demand, push for innovation, and facilitate the transfer of knowledge from foreign players. China has used this formula successfully in high-speed rail (Chinese companies have a 41 percent share of the global railroad-equipment revenues, according to McKinsey estimates), wind power, and telecommunications equipment. Learning and innovation have been slower to come in automotive manufacturing. To date, most domestic Chinese carmakers have relied on platforms from their global partners or on designs from outside firms to bring products to market quickly. Thanks to exploding domestic demand and strong profit streams from joint ventures, they have felt little pressure to innovate. Deregulation, a rapid increase in China's base of engineering talent, and continued high levels of government investment promise to make engineering-based companies more motivated and effective innovators in the future. In some sectors, such as nuclear power, explicit state support will continue to be critical. China has an ambitious government plan to build nuclear plants resulting in a total installed capacity of 58 gigawatts by 2020, which can support its goal of obtaining 20 percent of its energy from non-fossil fuel 
sources by 2030. Government programs to provide a boost even as a new generation of entrepreneurs draws from global knowledge and partnerships. A massive government push to raise R\&D spending, train more scientists, and file more patents has yet to give China a lead in science-based innovation. The slow progress has a number of explanations - not least that this type of work takes a long time to pay off and requires an effective regulator to protect intellectual property. Huge investments by government and the private sector to shepherd projects from the lab to commercial deployment are needed, as well. What's more, despite the large number of Chinese students trained in scientific and technical fields, companies struggle to find capable talent. Students can all do very well because they work much harder, and are very disciplined in a way. But China will take a long time to catch up - it has a lot of structural limitations on people and students.

\section{Summary}

China has been ranked third in the world for innovation by global business leaders, according to the GE 2018 Global Innovation Barometer1 Report released Friday in Shanghai. The technological innovation as an integrated science, technology, knowledge and economic factors such as human practical activity, not only changes in the socio-economic systems show a positive role in promoting, but also the pattern of activities through its unique role in the socio-cultural systems, changing the society's material culture, system culture, spiritual and cultural outlook. According to Merton's remarkable features and potential function of the division, through technical innovation and cultural perspective on the technological innovation with the rich social and cultural connotations, the cultural innovation and the outstanding features, social and cultural boundaries digestion function of the positive potential, triggering education change. Meanwhile, 73 percent of Chinese executives believed that China has an environment conducive4 to innovation education. As China transits to a more innovation-driven economy, an understanding of how businesses deal with this change is critical to operating in this education. Even as these reforms play out, Chinese innovators are adopting novel approaches-for instance, using the country's massive market size and huge pool of low-cost researchers to industrialize and speed up experimentation and data collection. The extent and speed of China's advances in innovation will have significant implications for the country's growth and competitiveness and for the types of jobs, products, and services available to the Chinese people. They will also have powerful consequences for multinationals (competing at home and abroad with Chinese companies), some of which are now using China as an R\&D base for global innovation. Fortunately, that isn't a zero-sum game: a more innovative China ought to be good for a global economy that seeks new sources of growth.

\section{Acknowledgements}

This research was financially supported by Beijing Information Technology College Research Subject. 


\section{References}

[1] Kalanit Efrat, The direct and indirect impact of culture on innovation[J]. Technovation,2014 (34) 12-20

[2] Michael Bungay Stanier, The Coaching Habit: Say Less, Ask More \& Change the Way You Lead Forever[m]. Box of Crayons Press, New York, 2016 